\title{
Scientific illustrations of SARS-CoV-2 in the media: An imagedemic on screens
}

\author{
Celia Andreu-Sánchez ${ }^{1 凶}$ \& Miguel Ángel Martín-Pascual (1) 1,2
}

The coronavirus disease 2019 (COVID-19) pandemic has caused an overload of scientific information in the media, sometimes including misinformation or the dissemination of false content. This so-called infodemic, at a low intensity level, is also manifested in the spread of scientific and medical illustrations of severe acute respiratory syndrome coronavirus 2 (SARS-CoV-2). Since the beginning of the pandemic, images of other long-known viruses, sometimes imaginary reconstructions, or viruses that cause diseases in other, non-human species have been attributed to SARS-CoV-2. In a certain way, one can thus speak of a case of an imagedemic based on an alteration of the rigour and truth of informative illustrations in the media. Images that illustrate informative data have an influence on the emotional perception of viewers and the formation of attitudes and behaviours in the face of the current or future pandemics. So, image disinformation should be avoided, making it desirable that journalists confirm the validity of scientific images with the same rigour that they apply to any other type of image, instead of working with fake, made-up images from photo stock services. At a time when scientific illustration has great didactic power, highquality information must be illustrated using images that are as accurate and real as possible, as for any other news topic. It is fundamental that informative illustrations about COVID-19 used in the media are scientifically rigorous.

\footnotetext{
${ }^{1}$ Neuro-Com Research Group, Audiovisual Communication and Advertising Department, Universitat Autònoma de Barcelona, Barcelona, Spain.

${ }^{2}$ Technological Innovation, Instituto Radio Televisión Española, Corporación RTVE, Barcelona, Spain. email: celia.andreu@uab.cat
} 


\section{Introduction}

/ live in the age of the image. Indeed, visual language is the dominant mode of communication of the 21 st century (Wagner and Diederik, 2016). However, the perception of visual content is not identical to the sum of qualities corresponding to the projected image (Arnheim, 1943). Thousands of studies are carried out annually to deepen knowledge on how visual perception works. Some of these lie in the field of psychology and others within neuroscientific areas, while many are in the regime of communication studies. And yet, questions regarding visual imagery and visual perception remain an open issue (Bértolo, 2005). Although being visually competent is important in real-life situations today, it seems that visual learning is a missed opportunity in some areas such as education (Kárpáti, 2020). Visual representations of scientific information in the media have an impact on audiences that are not always considered (Fagerlin et al., 2017; Thorpe et al., 2021). Scientific illustrations are great tools to educate audiences about scientific research. The media may be able to help to improve visual learning in the context of reproducing and designing scientific illustrations.

\section{Scientific illustration, research and communication}

There is a great historical tradition of scientific illustration linked to research. Back in the eighteenth century, some notion of realism was the declared aim in scientific imagery (Ford, 2003), whether for analytic or dissemination purposes. A good illustration can lead to a better understanding or facilitate the abstraction of concepts, facilitating new ideas or points of view. Their salience often makes it possible to highlight remarkable aspects by schematizing, modifying the colour or highlighting a shape (Wong, 2011), as shown, for example, by the careful neuroscientific drawings based on histological preparations by Santiago Ramón y Cajal. Based on brilliant intuition and hard work, he drew small arrows (Fig. 1) to represent his principle of dynamic polarization that indicated for the first time the direction of neuronal flow, from the dendrites, to the neuronal soma, to the axon and onto the next neuron (Delgado-García, 2015; Ramón y Cajal, 1904).

Such illustrations that enable an interpretation of the world through scientific results lead to great responsibility, not only in terms of summarizing the research process to peers but also in communicating those results to society, which is today more visual than ever. It is fundamental that informative illustrations used in the media are scientifically rigorous since they influence the public's perception of science, misinformation and problems that affect daily life (McCabe and Castel, 2008; Scheufele and Krause, 2019).

Illustrations that accompany research articles do not always seek to improve scientific understanding or achieve didactic excellence. Indeed, in the world of research, the manipulation or alteration of illustrations has also become a general problem. Recently, scientific publishers have initiated a joint effort to create an automated method to identify image alterations in research papers (Van Noorden, 2020) in an effort to recover the prestige, originality and rigour of high-quality scientific illustrations in this content. However, the problem of disinformation also includes the dissemination of scientific information in the media.

\section{Building the image of the SARS-CoV-2 coronavirus from science}

Real images of SARS-CoV-2 were obtained more than a year ago. On January 24, 2020, the Chinese Center for Disease Control and Prevention $(C C D C)$ revealed the first image of the coronavirus (Center National Microbiology Data, 2020). A few weeks later, on February 13, the Rocky Mountain Laboratories (RML), belonging to the National Institute of Allergy and Infectious Diseases (NIAID), shared high-resolution images of SARS-CoV-2 that were published in an open-access Flickr catalogue (De-Wit and Fisher, 2020). On March 5, the first higher-resolution cryogenic electron microscopy images were obtained by the Cryo-EM Centre of the Southern University of Science and Technology in Shenzhen (Liu et al., 2020) (Fig. 2a). Beyond such actual images, one of the first public-domain scientific illustrations of SARSCoV-2, designed in 3D (Fig. 2b), emerged on January 30, 2020 from the Centers for Disease Control and Prevention (CDC), creating an identity for the virus that would grab the public's attention (Eckert and Higgins, 2020; Giaimo, 2020). More recently, the company Nanographics with the collaboration of Tsinghua University provided a 3D illustration of SARS-CoV-2 obtained by cryo-electron tomography (cryo-ET), revealing its structure (Nanographics, 2021; Yao et al., 2020). Many electron microscopy images are presented in false colour today, to highlight or understand differentiated structures within the space (Fig. 2c). The aim is to enable a better interpretation of the colourless images obtained based on the transmission of electrons through a sample to the detector.

\section{Building the image of the SARS-CoV-2 coronavirus in the media}

As described above, the first real images of SARS-CoV-2 were obtained between January and March 2020 using various electron microscopy techniques. And yet, during the COVID-19 pandemic, the Web, broadcasters and the general press have frequently rushed to use illustrations related to SARS-CoV-2 that often did not correspond to the state of the art of science or that were chosen based on aesthetic criteria (Andreu-Sánchez and Martín-Pascual, 2020). It has been very common to see false, drawn, designed or interpreted images in three dimensions, sometimes even representing different or simply invented viruses, to illustrate information on the pandemic (Andreu-Sánchez and Martín-Pascual, 2020). The reference image used in the media and other sources on the COVID-19 pandemic is a retouched design image for illustration, in colour and three dimensions, rather than a real image (Andreu-Sánchez and Martín-Pascual, 2020). These fake, made-up images of the coronavirus, often obtained from repositories or paid stocks, are false information that receives great attention from citizens since journalists use them constantly. Moreover, such use of fake images to illustrate SARS-CoV-2 is not necessary since high-quality scientific illustrations have been available from before the start of the pandemic in March 2020. Thus, media have wasted their opportunity to help improve visual learning through scientific illustration.

In March 2015, a talk by Bill Gates alerted us of the possibility that a global virus could destabilize society as we know it (Gates, 2015). His words have taken on special meaning since the COVID-19 pandemic for obvious reasons. However, this extends from not only his words to including his images. Indeed, Gates showed a 3D model of the H1N1 influenza virus during his presentation, and several media used this image during the COVID-19 crisis in 2020 to illustrate information regarding the SARS-CoV-2 virus. This clear case of image disinformation is not unique. Many media are using depictions of viruses from cats or other animals, other diseases or respiratory coronaviruses other than SARS-CoV-2. Others have used made-up illustrations, which is also worrying. Paid repositories that index images as COVID-19 are the usual sources. Many of the most renowned mass media are using fake images of the coronavirus that do not correspond to the real SARS-CoV-2 virus when talking about it. One can see examples of this in information and news sources 


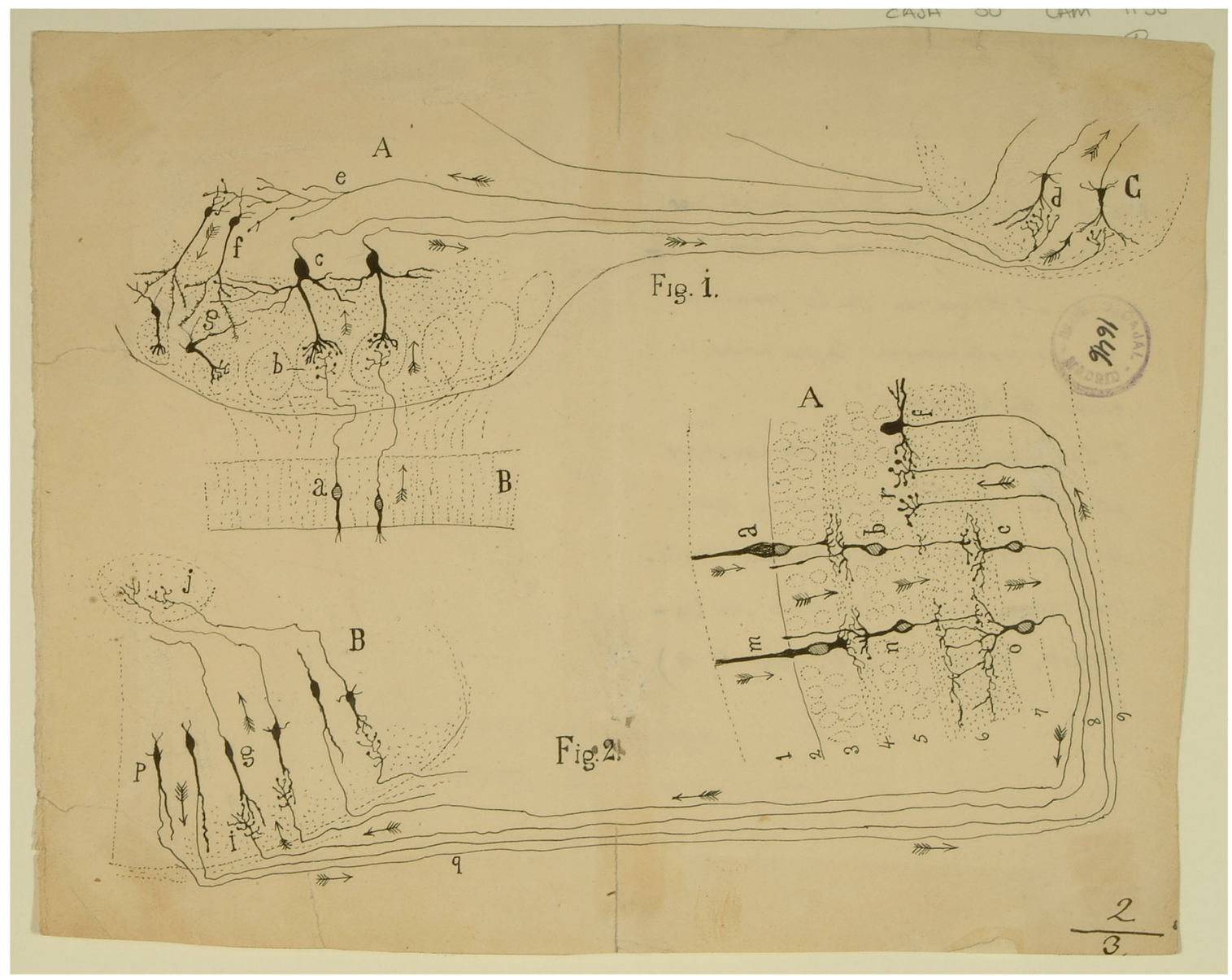

Fig. 1 Ramón y Cajal's drawing of nerve impulses corresponding to the olfactory and visual systems. Note the arrows that indicate the neuronal flow in a scientific illustration that introduces dynamic polarization, a hypothesis for functional analysis of the brain that remains relevant today. This figure is not covered by the Creative Commons Attribution 4.0 International License. Reproduced with permission of Juan A. De Carlos; copyright (c) Cajal Institute (Centro Superior de Investigaciones Científicas, CSIC), all rights reserved.
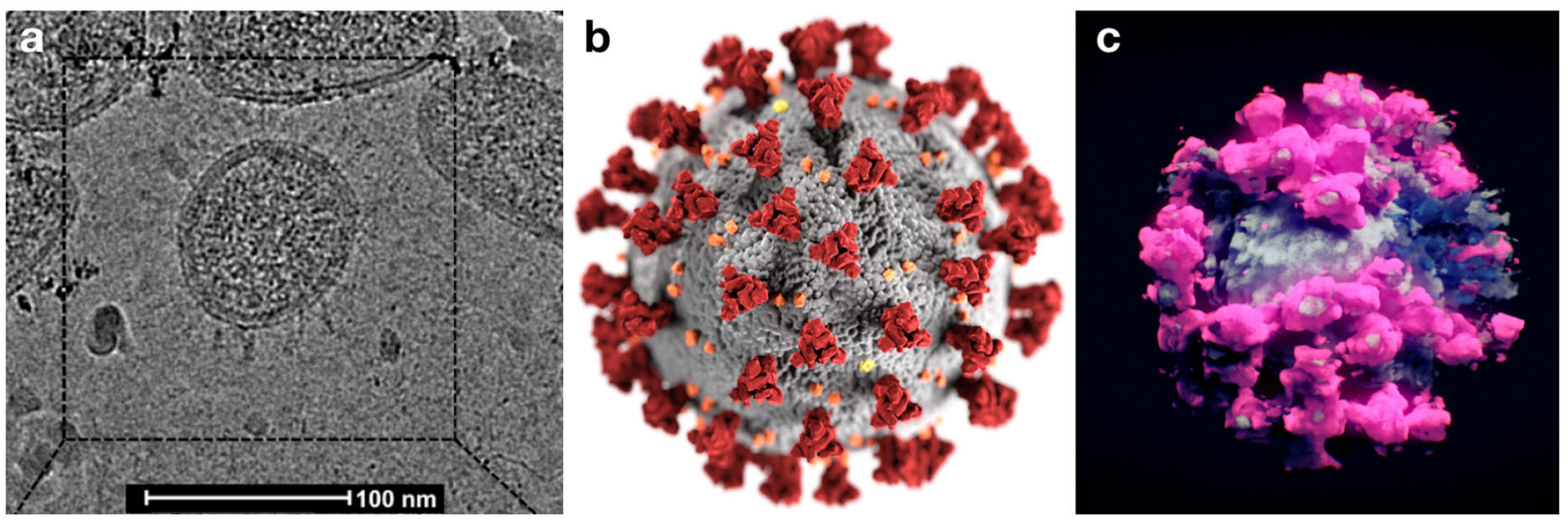

Fig. 2 Scientific illustrations of the SARS-CoV-2 coronavirus. a The first higher-resolution cryogenic electron microscopy image, obtained by the Cryo-EM Centre of the Southern University of Science and Technology. This figure is not covered by the Creative Commons Attribution 4.0 International License. Reproduced with permission of Professor Peiyi Wang; copyright (c) Cryo-EM Centre of SUSTech available at https://www.biorxiv.org/content/10.1101/ 2020.03.02.972927v1.full.pdf, all rights reserved. b Illustration created at the Centers for Disease Control and Prevention (CDC) by Alissa Eckert and Dan Higgins. Source CDC, public domain and thus free of any copyright restrictions at https://phil.cdc.gov/Details.aspx? pid=23312. $\mathbf{c}$ Infographic based on cryo-electron tomography, created in false colour by Nanographics using data from Tsinghua University. This figure is covered by the Creative Commons Attribution 4.0 International License. Reproduced with permission of Nanographics at https://nanographics.at/projects/coronavirus-3d/ copyright (c) Nanographics, all rights reserved. 

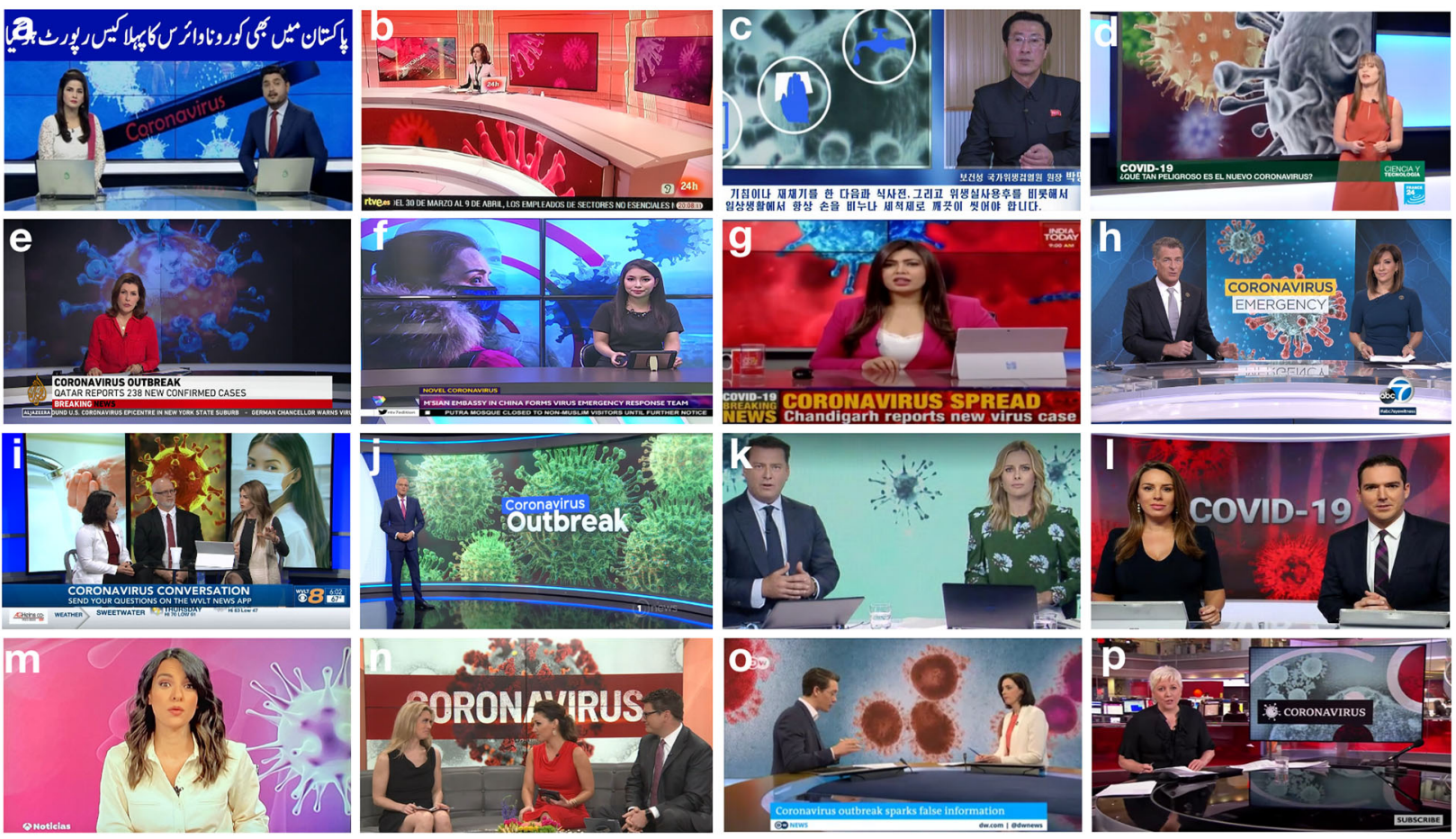

Fig. 3 Several television news programs with stage design and illustrations of SARS-CoV-2. a-m Fake coronavirus models or other viruses, $\mathbf{n}$ a scientific illustration, o, p real photos with retouched colour. Sources: a K21 News, Pakistan, b Canal 24horas RTVE, Spain, c Central Korea TV show, North Korea, d News in Spanish, France24, France, e News in Al Jazeera, Qatar, f NTV7, Malaysia, g News on India Today, India, h Local news in ABC, USA, i News in Channel 8 in CBS/MyNetwork TV, USA, j News in Nzdt, New Zealand, k Today this morning, Channel 9, Australia, I Sky News, Australia, m Antena 3 Noticias, Spain, n 8 Wish-TV, USA, o Deutsche Welle, Germany, p BBC News, UK. This figure is not covered by the Creative Commons Attribution 4.0 International License. Reproduced with permission of Andreu-Sánchez and Martín-Pascual; copyright (c) Andreu-Sánchez and Martín-Pascual, all rights reserved.

worldwide (Fig. 3). One cannot imagine using images of Barack Obama to illustrate a news story on Joe Biden, for example, or the constant use of artistic drawings of the White House when providing institutional information. However, in a way, this is what we have been seeing in most media when talking about COVID-19.

\section{Perception of SARS-CoV-2 images in the media}

During the first lockdown due to the pandemic in 2020, interest in information about COVID-19 resulted in an explosion of searches on the web, which is not always a verified activity, as well as on social networks and, above all, an increase in the audiences of public media. For example, in the European public communication services (PSM), the audience of public evening newscasts during the beginning of the lockdown in 2020 more than doubled compared with the previous year. It was concluded that, during that time of crisis, the young audience increased by $20 \%$ compared with usual figures (European Broadcasting Union, 2020). The educational contribution of these information services is important, making it necessary to ensure that illustrations of such information are true to reality. We know that images are an important component of the influence of informative narratives. The classic study by McCabe and Castel on the influence of the images that accompany information and advertisements revealed a large difference in the credibility given to the same text depending on the accompanying image, and how the public judges scientific reasoning differently according to the nature of such images (Andreu-Sánchez and Martín Pascual, 2014; McCabe and Castel, 2008). They showed that when an image of the brain or a functional magnetic resonance imaging (MRI) scan appears accompanying a scientific text, the content appears to be much more scientific and credible.

Although real, scientific, and even beautiful, free images of SARS-CoV-2 are available, many contents and news creators have opted for artistic, aesthetic, commercial stock illustrations and fake options when presenting information related to COVID-19. This has resulted in a chimera of disinformation that is distant from the appearance of the real coronavirus.

On February 15, 2020, Tedros Ghebreyesus-Adhanom, the director of the World Health Organization (WHO), said: "We're not just fighting an epidemic; we're fighting an infodemic" (Ghebreyesus Adhanom, 2020). If an image is worth a thousand words, we could modestly add that we are not just fighting an infodemic but also an imagedemic.

The use of fake images of SARS-CoV-2 seems to be a manifestation of a low-intensity infodemic that, although not representing a disinformation hoax, affects the rigour of the news to various degrees (Zarocostas, 2020). Since the formal attributes of an image, such as colour (von Goethe, 1810; Guilford, 1934), modify its perception, these erroneous illustrations cause emotional effects on viewers that are still difficult to assess (AndreuSánchez and Martín-Pascual, 2021). Coloured illustrations of SARS-CoV-2 in three dimensions are perceived as beautiful but not very realistic, scientific or didactic. By contrast, black and white coronavirus images are thought to be the opposite. Photographs of the coronavirus are perceived as much scarier than illustrations. The perceived beauty of the coronavirus images is negatively correlated with the perception of the didactic value and scientific realism of such images (Andreu-Sánchez and MartínPascual, 2021). Therefore, the formal characteristics, such as colour versus black and white, photography versus illustration, 
and two versus three dimensions, of an image of the coronavirus can impact audiences' perceptions of SARS-CoV-2 (AndreuSánchez and Martín-Pascual, 2021). In this context, it is desirable that journalists confirm the validity of scientific images with the same rigour that they would apply to any other type of image. Using commercial photo stock services to illustrate information about any scientific topic is not a good idea, just as it is not for illustrating any other type of information. The first step that a journalist should take when illustrating any scientific information is to look for scientifically rigorous images.

\section{Sources of information and mood in the photo stock era}

Today, computer-aided design technology allows the creation of hyper-realistic images that are barely distinguishable from photographs, and it is difficult to determine the degree of realism or schematization required of an informative illustration (Scheltema et al., 2018). Also, the influence of television and informative websites with lax controls to detect misinformation and for verification does not help. Many communication professionals use commercial photo stock services, which often do not offer illustrations with proper meta-data. The use of many massive stock services is producing an effect of unifying the photos presented in the media, which we find repeated everywhere, even creating archetypes that are far from reality in a wide variety of subjects. These influential visualizations in the media often summarize a topic or group through an illustration with a substantial and often reductionist bias (Thurlow et al., 2019). It is therefore apparent that media professionals, experts and illustrators must be highly aware of the effects of their work on the audience, in terms of both technical rigour and aesthetics. In the scientific ecosystem, the rigour of researchers' communication also seems to be insufficient.

Recent studies have shown how the mental processes that are activated when searching for or consuming information sources side-line reasoning to favour emotions, although this should not be prioritized for news consumption (Aslam et al., 2020). The emotional bias that can be evoked in consumers and information prosumers by images that accompany headlines is thus very important. The repetition of artistically altered or reproduced images of viruses from these photo stocks without rigorous meta-data can facilitate the dissemination of hoaxes and emotions that lack objectivity. The consequences of such misinformation do not always lead to fear; it can even facilitate the phenomenon known as unrealistic optimism, facilitating emotions and behaviours that contribute to increased deaths and exposure to risk (Gassen et al., 2021). An effective analysis of fake news must thus include illustrations as a factor related to emotional bias. Institutions such as the European Commission recommend an urgent and obligatory code, with respect to freedom of information, for the large online social platforms, portals and repositories (European Commission, 2021). It will be equally important to continue to improve detection tools to analyse the source of the generation of disinformation, including an analysis of informative illustrations and audio-visual content, as well as advertising inserts.

\section{Concluding remarks}

Medical and health information delivered by the media is of great value for citizens to make decisions regarding their health care (Schwitzer, 2008), and the form of visual presentations has an impact on the attention of the viewer (Andreu-Sánchez et al., 2018; Matta, 2020), thus such images should be treated seriously by the media.

In scientific communication, fake, confusing or lazy messages should be avoided. To achieve this, the sources of images must be verified to clearly distinguish scientific illustration, which may
Table 1 Some scientific Institutions that offer scientific images of the SARS-CoV-2 coronavirus.

Institutions Sources

National Microbiology Data Center https://nmdc.cn/nCov/en (NMDC), China

Centers for Disease Control and

https://phil.cdc.gov/default.aspx

Prevention (CDC), USA

National Institute of Allergy and

Infectious Diseases (NIAID), USA

Nanographics (in collaboration

with different institutions)

https://www.flickr.com/photos/

niaid/albums/72157712914621487

https://nanographics.at/projects/

sars-cov-2/

https://nanographics.at/projects/ coronavirus-3d/

also have artistic quality, from merely aesthetic images that have little to do with rigorous information. Media creators should avoid working with photo stock services instead of scientific sources when dealing with scientific and medical information. Also, the communication departments of scientific laboratories and institutions should create more usable images to illustrate their research in the media. While these communication departments are very used to managing textual information, they should develop a more ambitious strategy to create visual content for the media. Although some institutions have already shared scientific images of SARS-CoV-2 on their websites (Table 1), the vast majority of such images are found in scientific papers, which (sometimes) make it difficult for journalists to obtain the rights for their reproduction.

In the case of COVID-19, rigorous, real images of SARSCoV-2 should be used when possible, just as real images should be used as a rule to accompany any type of information. At this point of the COVID-19 pandemic, the audience may think they know how the SARS-CoV-2 looks, but maybe wrong. Far from being an anecdote, this represents a serious problem, since those fake COVID-19 images have an influence on the emotional perception of viewers. Journalists should avoid using fake images or images made by artists without scientist supervision because those are not faithful to reality. This is a matter of scientific rigour. We must also prepare audiences for the future waves of visual misinformation that will undoubtedly accompany the next global health emergency. More multidisciplinary studies on reception are needed in the cognitive sciences to guide the design of such communications as well as health programs.

Received: 29 July 2021; Accepted: 5 January 2022;

Published online: 19 January 2022

\section{References}

Andreu-Sánchez C, Martín-Pascual MÁ (2021) The attributes of the images representing the SARS-CoV-2 coronavirus affect people's perception of the virus. PLoS ONE 16(8):e0253738. https://doi.org/10.1371/journal.pone.0253738

Andreu-Sánchez C, Martín-Pascual MÁ (2020) Fake images of the SARS-CoV-2 coronavirus in the communication of information at the beginning of the first Covid-19 pandemic. Prof Inf 29(3):e290309. https://doi.org/10.3145/ epi.2020.may.09

Andreu-Sánchez C, Martín-Pascual MÁ, Gruart A, Delgado-García JM (2018) Chaotic and fast audiovisuals increase attentional scope but decrease conscious processing. Neuroscience 394:83-97. https://doi.org/10.1016/ j.neuroscience.2018.10.025

Andreu-Sánchez C, Martín Pascual MÁ (2014) Representation of neuroscience in advertising. In: Grabowski M (Ed.) Neuroscience and media: new understandings and representations. Routledge, New York, pp. 183-193

Arnheim R (1943) Gestalt and art. J Aesthet Art Crit 2(8):71-75. https://doi.org/ $10.2307 / 425947$ 
Aslam F, Awan TM, Syed JH, Kashif A, Parveen M (2020) Sentiments and emotions evoked by news headlines of coronavirus disease (COVID-19) outbreak. Hum Soc Sci Commun 7(1):1-9. https://doi.org/10.1057/s41599-020-0523-3 Bértolo H (2005) Visual imagery without visual perception? Psicologica 26(1):173-188

Center National Microbiology Data (2020) 新型冠状病毒武汉株01/C-Tan-nCov Wuhan strain 01. Novel Coronavirus National Science and Technology Resource Service System. http://nmdc.cn/nCov/en

De-Wit E, Fisher E (2020) Novel Coronavirus 2019. Rocky Mountain Laboratories visual medical arts, NIAID. Rocky Mountain Laboratories Visual Medical Arts, NIAID Flickr. https://www.flickr.com/photos/niaid/albums/72157712914621487. Accessed 29 Jul 2021.

Delgado-García JM (2015) Cajal and the conceptual weakness of neural sciences. Front Neuroanat 9(128):1-9. https://doi.org/10.3389/fnana.2015.00128

Eckert A, Higgins D (2020) Public Health Image Libray (PHIL). Centers for Disease Control and Prevention (CDC). https://phil.cdc.gov/details.aspx?pid=23312. Accessed 29 Jul 2021.

European Broadcasting Union (2020) COVID-19 PSM Audience Performance. European Broadcasting Union

European Commission (2021) European Commission guidance on strengthening the Code of Practice on disinformation. In: Communication from the Commission to the European Parliament, the Council, the European Economic and Social Committee and the Committee of the Regions.

Fagerlin A, Valley TS, Scherer AM, Knaus M, Das E, Zikmund-Fisher BJ (2017) Communicating infectious disease prevalence through graphics: results from an international survey. Vaccine 35:4041-4047. https://doi.org/10.1016/ j.vaccine.2017.05.048

Ford BJ (2003) Scientific illustration in the eighteenth century. In: Porter R (ed) The Cambridge history of science. Cambridge University Press, pp. 561-583

Gassen J, Nowak TJ, Henderson AD, Weaver SP (2021) Unrealistic optimism and risk for COVID-19 disease. Front Psychol 12(Jun):1-16. https://doi.org/ $10.3389 /$ fpsyg.2021.647461

Gates B (2015) The next outbread? We're not ready. TED. https://www.ted.com/ talks/bill_gates_the_next_outbreak_we_re_not_ready/discussion?. Accessed 29 Jul 2021.

Ghebreyesus Adhanom T (2020) Munich Security Conference. World Health Organization. https://www.who.int/dg/speeches/detail/munich-security-conference. Accessed 29 Jul 2021.

Giaimo C (2020) The spiky blob seen around the world. N Y Times. https:// www.nytimes.com/2020/04/01/health/coronavirus-illustration-cdc.html. Accessed 29 July 2021.

von Goethe JW (1810) Zur Farbenlehre (J. Cotta (ed.)). De la traducción castellana Teoría de los Colores. 1999. Celeste Ediciones, Madrid. Colegio Oficial de Arquitectos Técnicos de Murcia.

Guilford JP (1934) The affective value of color as a function of hue, tint, and chroma. J Exp Psychol 17(3):342-370. https://doi.org/10.1037/h0071517

Kárpáti A (2020) Visual literacy in the age of the image. In: Joseph S (Ed.) Humanistic futures of learning: perspectives from UNESCO Chairs and UNITWIN Networks. UNESCO, pp. 63-66

Liu C, Yang Y, Gao Y, Shen C, Ju B (2020) Viral Architecture of SARS-CoV-2 with post-fusion spike revealed by Cryo-EM. BioRxiv 1-17. https://doi.org/ 10.1101/2020.03.02.972927v1.abstract

Matta G (2020) Science communication as a preventative tool in the COVID19 pandemic. Hum Soc Sci Commun 7(1):1-14. https://doi.org/10.1057/s41599020-00645-1

McCabe DP, Castel AD (2008) Seeing is believing: the effect of brain images on judgments of scientific reasoning. Cognition 107(1):343-352. https://doi.org/ 10.1016/j.cognition.2007.07.017

Nanographics (2021) Real SARS-CoV-2 virion in 3D. https://nanographics.at/ projects/coronavirus-3d/. Accessed 29 Jul 2021.

Ramón y Cajal S (1904) Textura del sistema nervioso del hombre y los vertebrados (1899-1904). Nicolás Moya.

Scheltema E, Reay S, Piper G (2018) Visual representation of medical information: the importance of considering the end-user in the design of medical illustrations. J Vis Commun Med 41(1):9-17. https://doi.org/ $10.1080 / 17453054.2018 .1405724$

Scheufele DA, Krause NM (2019) Science audiences, misinformation, and fake news. Proc Natl Acad Sci USA 116(16):7662-7669. https://doi.org/10.1073/ pnas. 1805871115
Schwitzer G (2008) How do US journalists cover treatments, tests, products, and procedures? An evaluation of 500 stories. PLoS Med 5(5):0700-0704. https:// doi.org/10.1371/journal.pmed.0050095

Thorpe A, Scherer AM, Han PKJ, Burpo N, Shaffer V, Scherer L et al (2021) Exposure to common geographic COVID-19 prevalence maps and public knowledge, risk perceptions, and behavioral intentions JAMA Netw Open 4:e2033538. 10.1001/jamanetworkopen.2020.33538

Thurlow C, Aiello G, Portmann L (2019) Visualizing teens and technology: a social semiotic analysis of stock photography and news media imagery. New Media Soc. https://doi.org/10.1177/1461444819867318

Van Noorden R (2020) Publishers launch joint effort to tackle altered images in research papers. Nat News. https://www.nature.com/articles/d41586-020-014109? $\mathrm{utm} \_$source $=$Nature + Briefing\&utm_campaign $=\mathrm{a} 2 \mathrm{~b} 0 \mathrm{~b} 4 \mathrm{f} 54 \mathrm{f}$-briefing-dy 20200514\&utm_medium =email\&utm_term=0_c9dfd39373-a2b0b4f54f44193841. Accessed 29 Jul 2021.

Wagner E, Diederik S (eds) (2016) Common European Framework of reference for visual literacy-prototype. Waxmann.

Wong B (2011) Visual representation of scientific information. Sci Signal 4(160):1-4. https://doi.org/10.1126/scisignal.2001842

Yao H, Song Y, Chen Y, Wu N, Xu J, Sun C, Zhang J (2020) Molecular architecture of the SARS-CoV-2 virus. Cell 183(3):730-738.e13. https://doi.org/10.1016/ j.cell.2020.09.018

Zarocostas J (2020) How to fight an infodemic. The Lancet 395(10225):676. https:// doi.org/10.1016/S0140-6736(20)30461-X

\section{Acknowledgements}

The authors would like to thank Cambridge Copy and Translation SL for English style corrections.

\section{Competing interests}

The authors declare no competing interests.

\section{Ethical approval}

This article does not contain any studies with human participants performed by any of the authors.

\section{Informed consent}

This article does not contain any studies with human participants performed by any of the authors.

\section{Additional information}

Correspondence and requests for materials should be addressed to Celia AndreuSánchez.

Reprints and permission information is available at http://www.nature.com/reprints

Publisher's note Springer Nature remains neutral with regard to jurisdictional claims in published maps and institutional affiliations.

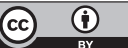

Open Access This article is licensed under a Creative Commons Attribution 4.0 International License, which permits use, sharing, adaptation, distribution and reproduction in any medium or format, as long as you give appropriate credit to the original author(s) and the source, provide a link to the Creative Commons license, and indicate if changes were made. The images or other third party material in this article are included in the article's Creative Commons license, unless indicated otherwise in a credit line to the material. If material is not included in the article's Creative Commons license and your intended use is not permitted by statutory regulation or exceeds the permitted use, you will need to obtain permission directly from the copyright holder. To view a copy of this license, visit http://creativecommons.org/ licenses/by/4.0/

(c) The Author(s) 2022 